\author{
Edyta Lorek-Jezińska*
}

\title{
Shakespeare, Authority and Hauntology: Postdramatic Performance in Walny Theatre's Hamlet
}

\begin{abstract}
The aim of this article is to explore the potential of hauntological theories to explain and problematise selected aspects of authority and performance in the context of Shakespeare's drama. Referring primarily to Derrida's and Abraham's concepts of the ghost and the phantom and their connection to Shakespeare's Hamlet, the article discusses hauntological perspectives on performance, both deconstructing and reaffirming authority. The paper comments on the relation between text and performance (Brook, Lehmann), memory and repetition (Carlson), disappearance and perpetual present (Phelan), as well as archive and repertoire (Taylor) in order to highlight the contradictory yet productive ways of understanding performance. The final part of the article, focusing on the significance of the ghost figure, examines experimental appropriations of Shakespeare's play in Walny Theatre's Hamlet (2015) in the light of postdramatic aesthetics.
\end{abstract}

Keywords: authority, hauntology, Shakespeare, Hamlet, postdramatic performance, Walny Theatre

The main objective of this article is to look at cultural presences of Shakespeare and the notion of the authority of performance from the perspective of hauntological theories and the concept of the spectrality of performance. ${ }^{1}$ Shakespeare's drama in general-and Hamlet in particular-has been instrumental both in inspiring the theory of hauntology by Jacques Derrida and the earlier psychoanalytic discussion on phantoms by Maria Torok and Nicolas Abraham and in supplying the material for the analysis of performance spectrality. I intend to examine the ways in which the hauntological aspects of

\footnotetext{
Nicolaus Copernicus University in Toruń, Poland.

1 This article was originally based on my paper presented during the symposium on "Shakespeare and the Idea of the Authority of Performance in Polish Theatre" in Łódź in March 2016. The starting point for the debate was the concept of the authority of performance and its multiple aspects discussed by William Worthen in his 1997 book. My aim was to place the concept of authority in the context of hauntological approaches to Shakespeare, Hamlet and the ghost figure.
} 
performance both deconstruct and reaffirm the concepts of authority. My focus is primarily on the context of postdramatic theatre and its reformulation of the relation between dramatic text and performance. My theoretical reflections will be based on the analysis of the experimental appropriations of Hamlet in the production of Hamlet (2010/2015) by Walny Theatre, founded by Adam Walny, a theatre director and puppeteer. While the performance will be explored for various implications of the ghost figure, which is a central metatheatrical character in Walny's performance, the article is primarily concerned with the productiveness of hauntological approaches in addressing sometimes contradictory aspects of authority and performance.

\section{Authority and Shakespeare}

The question of the authority of performance in Shakespeare's theatre involves a number of aesthetic, theoretical as well as political issues related to cultural status and the place of performance and text in the hierarchies of cultural production. In some periods and places, Shakespeare has been compared to "a cultural deity to whom even some of the most commercially minded producers and directors occasionally paid homage" (Levine 53). Attending a Shakespeare play has been described in terms of attending a mass in church with people "gratified that they have come", but simultaneously "gratified that they now may go" (Nachman qtd. in Levine 32). Despite this cultural cost of becoming a classic, Shakespeare has been argued to remain "one of the privileged sites around which Western culture has struggled to authenticate and sustain itself" (Fischlin and Fortier 8). This struggle contains both the centripetal tendencies of trying to consolidate Shakespeare into a specific and monolithic classical entity, on the one hand, and the centrifugal processes of using and appropriating Shakespeare for creating alternative identities and meanings, on the other. Both tendencies are linked to the questions of authority, in either building up the central cultural reputation of the original or in empowering the marginalised revisions of Shakespeare by increasing their cultural recognizability and visibility. ${ }^{2}$

An important question about the paradoxes of the circulation of Shakespeare in cultural production and about authority over its meaning was asked by Charles Marowitz:

The question is not, as it is so often put, what is wrong with Shakespeare that we have to meddle with his works, but what is wrong with us that we are

${ }^{2}$ See my discussion on the discourses of recycling, intertextuality and haunting in Shakespeare adaptations in Hauntology and Intertextuality in Contemporary British Drama by Women Playwrights (68-69). 
content to endure the diminishing returns of conventional dramatic reiteration; [...] not to realise that there is nothing so insidious as art that perpetuates the illusion that some kind of eternal truth is enshrined in a time-space continuum called a 'classic'. (Marowitz qtd. in Fischlin and Fortier 19)

When writing about the Deadly Theatre, Peter Brook considered Shakespeare's works to be one of the sites in which this type of theatre feels exceptionally comfortable: "nowhere does the Deadly Theatre install itself so securely, so comfortably and so slyly as in the works of William Shakespeare" (12). At the same time, Brook argues that the text of Shakespeare's plays refrains from taking authority over production, by reducing the written words practically to the lines to be spoken only. By expressing the belief that "the best dramatists explain themselves the least" Brook suggests that the rest belongs to the productive process that should "parallel the original creative one" (15). While questioning the belief that there is some specific way of acting Shakespeare that we can reconstruct and perpetuate, Brook posits the possibility of producing the same text in a different creative process which will be parallel to-but not the same as - the original. Nevertheless, the belief in the hypothetical presence of the original creative process in the text only transfers the authority over the production to the less visible process which can be contained metaphorically in the expressions associated with haunting and the dead, such as "the ghostly hand of "Shakespeare" (Worthen 98) or in the phrase used by Peter Stallybrass when commenting on Marjorie Garber's Shakespeare's Ghost Writers, which is about "how the dead hand of Shakespeare continues to write us" (Stallybrass qtd. in Garber xv).

The other aspect of the haunting concept emphasises the ability possessed by the living to "converse with" the ghosts of Shakespeare. In their introduction to an anthology of adaptations of Shakespeare's plays, Fischlin and Fortier point out how Marowitz's attitude exposes the importance of adaptation as reception, adding that it is both "a poetics of performative presence" and "textual revisioning that marks how the living speak to (and for) the dead" (19). Speaking to or for the dead involves the appropriation of the ghostly voice of Shakespeare, using its authority but also actively rebuilding and transforming the long history of Shakespeare's classical status.

\section{The "true" meaning of Hamlet}

Laura Bohannan's account of her story-telling experience with Hamlet which she had when living with the Tiv people (a West African tribe) in the 1960sfamiliar to many Shakespeare scholars and anthropologists-is often mentioned to emphasise both the universal dimension of Shakespeare and his cultural 
specificity. Her tale shows the extent to which the seemingly universal narrative is reinterpreted by the elders of the tribe and how naturally the listeners take over the authority of the story. Bohannan presents her effort to negotiate between her European / American understanding of Hamlet by Shakespeare with the cultural concepts and linguistic meanings available to her in the Tiv language. The commentary expressed by the listeners at the end of the story provides a surprising twist in the reversal of authority and role-attribution:

"That was a very good story," added the old man, "and you told it with very few mistakes." [...] "Sometime," concluded the old man, gathering his ragged toga about him, "you must tell us some more stories of your country. We, who are elders, will instruct you in their true meaning, so that when you return to your own land your elders will see that you have not been sitting in the bush, but among those who know things and who have taught you wisdom." (Bohannan, "Shakespeare in the Bush")

Bohannan's story is mentioned here for two reasons: firstly, to highlight the location of the authority not in the text itself or even the culture in which it was produced, but appropriated by those who believe to have a better insight into the meaning of the story - the elders. What can appear striking to a European or a "westerner" is the unproblematic nature of the act of taking control over the text's meaning. The second aspect, which is significant for the hauntological approach to Hamlet, refers primarily to the fundamental change of the interpretation of the story caused by a different understanding of the ghost figure. To the tribe who does not believe in afterlife for people, a ghost can only exist as a product of a witch's magic actions. Such a perspective denies "authority" not only to the author of the "story" but also to the ghost. In this tribal version the ghost, a tool in the hands of evil witches, cannot be seen as an independent character and the "author" of the story of his own death by poisoning.

\section{Hauntology and phantomistics of Hamlet}

To look at Hamlet from the perspective of hauntology and so called phantomistics (Royle 278) is to retell the story from the position of the ghost figure in its several meanings and implications. In this process the ghost becomes a central figure in which the meaning is locked. Thus what Jacques Derrida and also Nicolas Abraham argue is in fact an ontological and hermeneutic explanation of the play's meaning through the figure of the ghost. In Derrida's approach the text which is by definition haunted always contains the openings through which whatever Other can enter and which makes it impossible to enclose or restrict the text in its meaning. The ghost, according to 
Derrida, represents "something that one does not know, precisely, and one does not know if precisely it is, if it exists, if it responds to a name and corresponds to an essence" (Derrida 6) and this lack of knowledge is caused not by ignorance but by awareness of the impossibility to contain it in traditional and available conceptual categories. The Other speaks the language that we might not be able to understand and we should be able to accept the text's openness. Davis associates Derrida's ghost with "the structural openness or address directed towards the living by the voices of the past or the not yet formulated possibilities of the future" (Davis 379). This also implies that there is no possibility of narrowing down the text's meaning and that this impossibility also extends to the author of a text. ${ }^{3}$ The text haunted by a ghost, such as Shakespeare's Hamlet, is by definition troubled by ambiguity, multiplicity of meanings, contradictions, disturbed structure, anachrony, incompleteness, openness, uncertainty and deception.

The psychoanalytic approach to the figure of the phantom also sees literary texts as open and ambiguous, yet the role of the psychoanalytic critic is to cure the text of its ambiguity by addressing the secret guarded by the ghost. In Abraham's approach the reader needs to discover the secret that the ghost tries to protect by his or her deceptive strategies. Meaning, according to Abraham, can be decoded but only through psychoanalytic therapy, in which the phantom's deception is revealed. The author might be also subject to this deception, and thus unable to see the text's meaning. Similarly to the elders of the tribe, Abraham offers the explanation of the meaning of the text of Shakespeare's Hamlet, suggesting that the story is in a sense defective and it requires the additional closing sixth act to be added to Shakespeare's text. Abraham's final act tries to explain the play's enigmas and ambiguities, creating a coherent theory of the original text's meaning and prioritizing the function of the phantom in it. Abraham insists that "[t]he final scene of the Tragedy of Hamlet does not close the dramatic action, it simply cuts it off" (187) and its silence-or omission - contains the story that has a secret that needs to be disclosed. One of the crucial observations made by Abraham is that all the characters in the play are in fact the puppets of an evil phantom (188) and they are caught between two subconscious inclinations: to reveal the truth and to keep it secret. The ghost's revelation is just a subterfuge to mask the shameful secret that the ghost intends to keep safe. The audience is exposed to the complex psychoanalytic process, which according to Abraham, explains the "our centuries-long fascination with Hamlet must be credited to the 'phantom effect' in us" (190). Abraham's aim in writing the explanatory sixth act is "to 'cure' the public of a covert neurosis the Tragedy of Hamlet, has, for centuries, inflicted upon it" (190), by explaining

3 See my discussion on Shakespeare and hauntology in Hauntology and Intertextuality in Contemporary British Drama by Women Playwrights (23-24, 27, 29-30, 36). 
the motives of the phantom and reducing the gravity of the sin associated with the phantom's secret. In Abraham's approach Shakespeare leaves us with the legacy of the phantom effect in which he is in fact an accomplice. The text seems to require an interpreter by definition, the one who can explain the complexity of its psychological impact. In both Derrida's and Abraham's concepts of the haunted text of Hamlet, Shakespeare is denied the control and authority, and even perhaps the authenticity of the text. I shall return to the hauntological approach to Hamlet in the final part of my paper to comment on the fascinations with the ghost figure in Walny's performance, in which this problematic approach finds very tangible applications.

\section{Hauntology and performance}

The two approaches to hauntology can have different implications for the understanding of performance and its relation to text, and indirectly to the question of authority. In the phantomistic perspective, Shakespeare can be conceptualised as a body of cultural practices and meanings accumulated over the centuries, including the ideological appropriations involved, for example, in the formation of the literary or dramatic canon and in the colonial and imperialist domination of Western culture over the colonized nations and groups, among others. The phantom of Shakespeare and other metaphors related to his authority (e.g. "the ghostly hand of Shakespeare" mentioned earlier) might be connected with the persistence of certain privileged ways of reading his plays. In this process alternative readings are suppressed because of the cultural constructions of Shakespeare as a master or authority, and perhaps even more importantly, seeing Shakespeare as the means of empowerment or 'signifier of civilization' (cf. Orkin qtd. in Fischlin and Fortier 12). We might link this distinction to the differentiation between strategies and tactics introduced by Michel de Certeau: strategies of reading texts are defined by the author as the owner of the text, while tactics are worked out by readers, whose status is compared to a poacher. The former can be connected with the stability of the cultural space in which certain meanings are imposed while the latter-to unstable practices having no foundation in ownership or legitimacy (De Certeau 38-39). Each attempt at resorting to the stable authority of Shakespeare's text might be connected with the imposition or negotiation of cultural space for a 'legitimate' meaning. With the development of participatory cultures, as Henry Jenkins aptly notes when discussing fandom, poaching itself can turn into a form of art (28), taking control over the author's territory.

However, my intention behind referring to the theory of hauntology in theatre and performance is to focus on a different perspective, developed, among others, by Marvin Carlson and largely based on the radical version of the theory 
of intertextuality. This approach is primarily concerned with the concept of cultural memory that defines the experience of theatre. Like Derrida's revenant, who begins its existence by reappearing (Derrida 11), performance is constituted by repetition - by the return of the past text, known narrative or previous productions (Carlson 165).

In his book The Haunted Stage, Marvin Carlson presents the theatre as a "memory machine" whose fundamental principle are the acts of returning (theatre is "obsessed always with things that return") (15) and of retelling stories already known to the audience (18). What is quite important, this act of retelling - of recycling the familiar material - encourages comparison and exposes the new way of telling a familiar story. Therefore, as Carlson observes, "in a kind of paradox the author uses a familiar story to emphasize the originality of his contribution" (27). ${ }^{5}$

What is exposed in Carlson's idea of haunting and cultural memory is the paradoxical dependence between tradition and innovation: "a part of the cultural memory of Hamlet has become that it is a kind of 'test' for aspiring young actors, creating a special reception paradox wherein an important part of the audience expectation has become what the new actor will do to establish his own Hamlet" (81). Translating this process into the hauntological discourse, Carlson argues that in the Anglophone tradition Hamlet is the role that "evokes the most crowded field of ghosts" (81). Speaking of challenging the past interpretations of the character does not involve any assumption of the authentic or original performance to be established or recreated. In fact, it means replacing the ghosts of the past interpretation with the version that will now haunt the productions to come: Carlson writes of "producing a new ghost to haunt future interpretations" (85). Other aspects of haunting include the remains or residue of past roles played by an actor in a new role (Carlson 90). When Carlson briefly mentions the dramatic text as a point of reference in the Western tradition (in contrast to Japanese Noh theatre), he still sees the text only as a background against which memories of former productions are compared: "The echoes evoked by the performance are not of previous experience with the same basic configuration of stimuli but of the same grounding literary text and its implied patterns of action conceived by a different interpretive ensemble in different ways" (99). A new interpretation "often quite consciously evokes the ghosts of previous interpretations" (Carlson 101). It seems that in this perspective, the original has no authority over the productions that follow it. Every performance enters into intertextual relations with any other productions

${ }^{4}$ One of the interesting metaphors of this perspective is described in the context of Noh theatre warrior plays, where the ghost of the hero takes the same position as the audience looking back at the events that are familiar (Carlson 23).

5 Carlson here refers to the principle on which the competition in ancient Greek drama was based and it involved comparison of several versions of the same story. 
that a spectator is familiar with, and it gains its meaning in relation to them, with the process happening both diachronically and synchronically. In the concept of the haunted stage, performative memory seems to erase the memory of the text, which belongs to a different order of experience. This memory is primarily defined in terms of haunting, in which the actual experience of a performance is always a repetition, a return:

any theatrical production weaves a ghostly tapestry for its audience, playing in various degrees and combinations with that audience's collective and individual memories of previous experience with this play, this director, these actors, this story, this theatrical space, even, on occasion, with this scenery, these costumes, these properties. (Carlson 165)

However, haunting can also refer to the aspect of performance that seems almost contrary to Carlson's concept of memory machine. ${ }^{6}$ Performance is often conceptualised as existing in the present time only, unavailable to us in any other form, not even in documentation. The ontological status of performance is defined by the sense of disappearance, which is attributed by Derrida to the ghost figure representing the opening or a gap- "being-there of an absent or departed one" (Derrida 6). Peggy Phelan emphasizes the impossibility of the performance to exist beyond its actual happening: "[t]heatrical performance is always bound to the present. For this reason, theatre continually marks the perpetual disappearance of its own enactment" (118). What is interesting, Phelan's concept of disappearance implies a deliberate and conscious strategy: "I am speaking here of an active vanishing, a deliberate and conscious refusal to take the payoff of visibility" (19). This strategy produces "the unmarked", which refers to what is immaterial and "shows itself through the negative and through disappearance" (Phelan 19). If we translate this mode of writing into the relation between performance and text, Phelan sees an opportunity for the text to learn from performance how to overcome the reproductive economy of writing based on equivalence and replacement and to write "toward disappearance" (148). This type of writing is the only one that can form a language to address some of the idiosyncrasies of performance.

The concepts related to hauntology have been employed also in other contexts of performance to emphasise its ephemeral qualities. In site-specific theatre, the texture of performance is described by McLucas and Pearson through the metaphor of the ghost haunting the site. The site is conceptualised as

6 Phelan refers to memory in a slightly different context: she underlines the unrepeatability of theatre in either a new performance of the same production or in documentation, yet she admits that a document can (only) be "a spur to memory, an encouragement of memory to become present" (146). And it is in this sense that performance operates through memory in her approach. 
a host, a stable component defined by physical attributes, use and history, while a performance with its text, music and movement-is represented through the metaphor of a ghost recently and temporarily haunting the site, with the audience taking the role of the witnesses of haunting (Kaye 213, 220). Memory is primarily attached to the host while the performance (including the text) is just a temporary and fleeting occupation of the site in which such memory might be activated.

It seems that in the concept of theatre as a memory machine text and performance tend to be seen as belonging to different orders of existence, with the performance studies having a tendency to marginalise the authority of the text. Eagleton's commentary quoted in Worthen's discussion of Shakespeare and the authority of performance, refusing to see the text and theatre as opposites that complete each other in dichotomies of rest and action, death and life or corpse and ghost (21) can be complemented with Diana Taylor's concepts of "archive" and "repertoire" and their relation to cultural memory. Archival memory refers to the enduring materials that can be stored and reproduced, such as texts, maps, films, or buildings. They last over time and space, and are separated from its creator, but are subject to new interpretations. Repertoire, according to Taylor, "enacts embodied memory" and includes all the acts that are "ephemeral" and "nonreproducible" such as performance, movement, oral transmission or dance (20). Taylor insists that they are not antithetical but they are sometimes discussed as opposites because archive is often perceived as hegemonic while the repertoire as anti-hegemonic. However, performance can be a part of repertoire and support the hegemonic cultural forms and vice versa (22). Western cultures tend to privilege the written archive as the source of memory over repertoire.

Repertoire is described as being "in a constant state of againness" (21), which seems to be defined in contrast to the stability of the archive. However, in individual experience archive is made available to us through brief encounters; its first experience cannot be recreated - the text can be only revisited, perhaps in equivalent manner to how the experience of performance cannot be recreated but can be recalled aided by performance documentation. In individual experience both the text and performance are defined through the metaphor of the revenant and againness. The text as performed in a reading process and a performance as experienced in a specific moment are equally performative and defined by disappearance.

\section{Postdramatic theatre and Walny Theatre's Hamlet}

Postdramatic theatre, in the context of which I intend to place the production of Hamlet by Walny Theatre, is defined by Hans-Thies Lehmann as "a theatre that feels bound to operate beyond drama, at a time 'after' the authority of the 
dramatic paradigm in theatre" (27). However, what is significant, it does not reject totally the dramatic theatre, but drama persists - "however weakened and exhausted"- "as an expectation of large parts of its audience" and as a point of reference in redefinition and questioning. Dramatic theatre still exists as "the space of memory" (27). According to Lehmann postdramatic theatre depends on the recognition of the contradictory nature of the relationship between theatre and drama and the importance of "mutual emancipation" (46). In this context, the dramatic text is merely one of many components of theatre and the gap between the text and performance is often exposed as "an openly exhibited discrepancy or even unrelatedness" (46). The concept of the linguistic text is substituted by the performance text, which embraces all elements of performance, including the linguistic text as well (if there is any) (85). Postdramatic theatre defines the relation between text and stage as a "perpetual conflict", which, being inevitable, often becomes the deliberately employed principle of staging (145). Lehmann refers to what the Italian director of avantgarde theatre-Giorgio Barberio Corsetti notes about the use of the text in postdramatic theatre - "theatre needs the text as a foreign body, as a "world outside the stage" so as not to "get lost in the permanent self-thematization of the opsis", which refers to the rapidly expanding visual components of a spectacle (146). The term that Lehmann suggests for the text in postdramatic theatre - is the textspace - the term which emphasizes "the phonetic materiality, the temporal course, the dispersion in space, the loss of teleology and selfidentity" (148).

With the awareness of a much longer history of theatre that could be described as non-dramatic (Bauhaus, futurist, Dadaist, surrealist, street theatre, environmental, site-specific, performance art, dance and physical theatre and many others) than the one examined in Lehmann's book, I have decided to use the context of postdramatic theatre for Walny's performance to expose the mechanisms of "perpetual conflict" between the history of Shakespearian productions, the audience's expectations and Walny's performative strategies. Walny's experimental production of Hamlet as a performance enacted by a puppeteer operating large "submarine" marionettes and a Bunraku doll, raises a number of questions about the authority of performance and Shakespeare, the significance of the ghost figure in Hamlet, the relation between text, performance text and performance and the domination of the opsis to the point of absurdity. In order to react to Walny's experimental retelling of Hamlet and notice its transgressive strategies, the audience needs to confront not only the text of Shakespeare's play but also the earlier productions of his plays. If we set the lifeless puppet lying in back of the stage against the history of Hamlet's impersonations, we notice both the travesty of Walny's project and a significant repositioning of the characters that might evoke a different way of reading the familiar text, additionally reverberating with other productions and appropriations, such as Tom Stoppard's Rosencrantz and Guildenstern are Dead. 
The element of Walny's performance that particularly refers to the question of authority is the role played by the marionette operator. The performance builds upon and plays with the connections and equivalences between the ghost figure, a role of a puppeteer and the metatheatrical presence of what could be called implied Shakespeare. It presents the story of Hamlet as the ghost's story, as the play enacted and choreographed by he ghost, with the marionettes controlled and speechless. The "characters" in the production inhabit different orders of existence - the marionettes are submerged in water in large glass containers, while the Bunraku marionette representing Hamlet is brought to life only when operated by the puppeteer and most of the time is lying shapeless on the stage floor. This suspension or even abandonment of the puppets builds equivalent metatheatrical and existential tensions to Stoppard's Rosencrantz and Guildenstern are Dead (both play and film) and the interaction between the front stage and backstage drama. The story, narrated from the position of the ghost enacted by the live performer/puppeteer, starts with the announcement of the time for revenge. Doing his penance because of his treacherous brother and wandering the earth at night, the ghost decides to wake up the figure of Hamlet to start the revenge and enact a condensed story known from Shakespeare's Hamlet. Upon telling the story, the ghost/puppeteer seems relieved and is released from his confinement. The implied author's role performed by the puppeteer is suggested by the costume worn by him, the one that is supposed to resemble the cliché of the Elizabethan costume and the image of Shakespeare. Thus in a rather accidental correspondence to Abraham's phantom effect in Hamlet, Walny's performance presents the act of haunting as happening both within and outside the story, in reference to the ghost figure and Shakespeare as repentant story-tellers. The role enacted by the Bunraku puppet is reduced to the one of the tool in the ghost's hands, manipulated by him to lead to his final release. In that it resembles closely Abraham's interpretation of Hamlet as developed around the Ghost's subterfuge, mentioned earlier in the article. Looking at Walny's performance through the prism of phantomistics exposes the cutting off — instead of closing — of the story by a sudden movement into a metatheatrical and existential commentary in a form of a playful song on the fate of great historical figures, taken from the gravedigger's scene. The final line refers to memory and its failures, as if the only possibility of concluding the story would be to forget it. The ghost is brought to life by memory and then relieved from life and performance through forgetting, while the performance itself derives its meaning from memory of the text and its more faithful adaptations.

The performance space in Walny's Hamlet enacts the metaphorical imprisonment of characters in Shakespeare in what seems to be almost a travesty of the dramatic text. The text that the ghost repeats narrates other characters but also himself. The performance presents the nature of theatre through the visual 
metaphor of incapacitation and manipulation. By visualizing what might be seen as a commentary on the constrictive nature of theatrical tradition and memorybased expectations, the performance paradoxically subverts those expectations by offering an image to haunt the audience's future memory.

In its visual originality, if we disregard its cultural inaccessibility, Walny Theatre can be claimed to have produced, to use Carlson's expression, "a new ghost to haunt future interpretations" (85). In Walny's Theatre the opsis dominates and strikes with inventiveness and innovation but also its surrealist absurdity. The text spoken by the marionette operator and the ghost figure in one integrates this unusual imagery, by a skeletal narrative that gives sense to the visual image. It seems that it performs the function attributed to text in postdramatic theatre - to ground the surrealist image in the outside framework of the familiar story. Similarly to postdramatic theatre, the performance exposes the text as a foreign body, which is particularly visible in the artifice of a ventriloquist role played by the live actor. In the same way as he speaks through the figures of the characters, he is also ventriloquized by the fragmentary text of Shakespeare's play. The actor's metatheatrical presence distances him from the story he is telling and from the text he uses to explain the visual performance. ${ }^{7}$ Furthermore, Walny's performance exposes one of major conflicts in post-dramatic theatre - the one between text and performance, which is primarily visible in the fragmentation of the text and the way in which it is used in performance as alienated from the speechless marionette characters. It could be suggested that Walny's production goes even further in exposing the conflict by placing it within the performance text itself. This is primarily seen in the tensions developed between performance and exhibition, between an actor and an exhibit. Between the scenes in which the characters are briefly awakened by the puppeteer they fall into lethargy and, being framed by the glass display cabinet, they seem like alcohol-preserved animal exhibits. When the performance ends, the ghost actor exits the playing area, leaving the marionettes behind. They can be seen by the audience in the lifeless form after the performance as the remainder of its temporary liveliness. Walny's Hamlet is also a commentary on the relation between text, opsis and action, which is problematised in the act and metaphor of haunting.

${ }^{7}$ In another project realised by the artist-Opus Hamlet, there is no spoken or written text presented at all — the tragedy of Hamlet is enacted by the figures operated by live performers and they are primarily experimental musical instruments. Dialogues are realized as exchanges between the sounds produced by different instruments integrated with the rather abstract representations of metal frame shapes in which we can recognize human figures. It is quite apparent that the performance relies on the audience's familiarity with the narrative of Hamlet and the absence of the text in performance is only the proof of the extent to which the cultural memory of the story - in whatever version - is activated in performance - in fact haunts it. 
The tensions between these elements enter into various configurations with the site in which the performance is produced. The mini-playing area in which the performance is staged occupies only a portion of the normal theatre stage, creating the play-within-the-play and mise-en-abyme effect. The abandoned stage within the empty playing area exposes the aspects of presence and disappearance, which is particularly evocative in the production by a ghostly puppeteer. In outdoor settings, such as a park, in which Walny's productions also took place, the abandoned theatre set resembles a museum of theatre history preserved in lifeless exhibits, strikingly incongruous with the surrounding mobility.

Because of its scale and experimental marginality, Hamlet by Walny Theatre perhaps cannot be described as a ground-breaking production of Shakespeare. However, for the same reasons, it is a perceptive and symptomatic commentary on the authority and place of Shakespeare in contemporary theatre and culture. The metaphor of museum exhibits artificially preserved in glassy containers conveys both the fascination with and the exhaustion of Shakespeare as a reproducible cultural commodity. In fact, Walny's performance re-enacts the process of the cultural circulation of Shakespeare's drama, its repetitive revivals and resurrections. Containing Shakespeare in a concept of metatheatrical haunting raises questions of authenticity and authority. Being part of the repertoire rather than the archive, the production comments on the nature of performance and its poetics of disappearance.

\section{WORKS CITED}

Abraham, Nicolas. "The Phantom of Hamlet or The Sixth Act Preceded by The Intermission of "Truth"' (1975). The Shell and the Kernel: Renewals of Psychoanalysis. Ed. Nicolas Abraham and Maria Torok. Trans. Nicholas T. Rand. Chicago, London: University of Chicago Press, 1994. 187-205.

Bohannan, Laura. 1961. "Shakespeare in the Bush." Natural History Magazine. n. pag. Web. 10 February $2016 \mathrm{http} / / / \mathrm{www}$.naturalhistorymag.com/picks-from-thepast/12476/shakespeare-in-the-bush.

Brook, Peter. The Empty Space. London: Penguin Books, 1990.

Carlson, Marvin. The Haunted Stage: The Theatre as Memory Machine. Ann Arbor: University of Michigan Press, 2003.

Davis, Colin. "État Présent: Hauntology, Spectres and Phantoms." French Studies. 59 (3) 2005: 373-379.

De Certeau, Michel. The Practice of Everyday Life. Berkeley: University of California, 1984.

Derrida, Jacques. Specters of Marx: The State of the Debt, the Work of Mourning and the New International. Trans. Peggy Kamuf. London: Routledge, 2006. 
Fischlin, Daniel and Mark Fortier. "General Introduction." Adaptations of Shakespeare: A Critical Anthology of Plays from the Seventeenth Century to the Present. Ed. Daniel Fischlin and Mark Fortier. London: Routledge, 2000. 1-22.

Garber, Marjorie. Shakespeare's Ghost Writers. New York, Abington: Routledge, 2010.

Jenkins, Henry. Textual Poachers: Television Fans and Participatory Cultures. Taylor \& Francis e-Library, 2005.

Kaye, Nick. Art into Theatre: Performance Interviews and Documents. Amsterdam: Harwood Academic Publishers, 1996.

Lehmann, Hans-Thies. Postdramatic Theatre. London Routledge, 2006.

Levine, Lawrence W. Highbrow/Lowbrow: The Emergence of Cultural Hierarchy in America. Cambridge: Harvard University Press, 2002.

Lorek-Jezińka, Edyta. Hauntology and Intertextuality in Contemporary British Drama by Women Playwrights. Toruń: Nicolaus Copernicus University Press, 2013.

Phelan, Peggy. Unmarked: The Politics of Performance. London, NY: Routledge, 1993. Royle, Nicholas. The Uncanny. Manchester, NY: Manchester University Press, 2003.

Shakespeare, William. The Tragedy of Hamlet, Prince of Denmark. Hamlet (The Arden Shakespeare). Ed. Harold Jenkins. London, New York: Routledge, 1990. 165-419.

Taylor, Diana. The Archive and the Repertoire: Performing Cultural Memory in the Americas. Durham and London: Duke University Press, 2003.

Walny Theatre. Hamlet. Live performance at Klamra Theatre Festival (23 Akademickie Spotkania Teatralne), Toruń, 2015.

Worthen, William B. Shakespeare and the Authority of Performance. Cambridge: Cambridge University Press, 1997. 